\title{
Equality of Outcome or Equality of Opportunity? A Simulation of Wealth Distribution Using Agent-based Modeling
}

\author{
Ozgur Ekmekci ${ }^{1}$ \\ ${ }^{1}$ The George Washington University, Washington, DC, USA \\ Correspondence: Ozgur Ekmekci, EdD, The George Washington University, Washington, DC, USA. Tel: \\ 202-994-1623. E-mail: ekmekci@gwu.edu
}

Received: April 22, 2013

Accepted: May 20, 2013

Online Published: June 30, 2013

doi:10.5430/rwe.v4n2p1

URL: http://dx.doi.org/10.5430/rwe.v4n2p1

\begin{abstract}
Against the backdrop of calls for a more just form of capitalism, this paper specifically focuses on the notion of equality within capitalist societies and utilizes findings from a computer simulation to explore which of one two fundamental principles, namely: (1) equality of opportunity; or (2) equality of outcome might better inform and guide reform efforts to create more uniform distribution of wealth among members of society. In this study, Agent Based Modeling (ABM), as a form of computer simulation was used to explore how the fundamental principles of equality of opportunity or equality of outcome might impact wealth distribution in a capitalist society. A total of 800 simulations were run, where 400 of them incorporated the principle of equal opportunity and 400 incorporated the principle of equal outcome. Each of the 800 simulations covered a period of 5 years. The most interesting insight gained from this study is likely the finding that wealth distribution inequality is significantly lower if the distribution of wealth is grounded in the principle of equal opportunity, instead of being grounded in the principle of equal outcome. The other interesting finding is that the mean wealth, maximum wealth, and total wealth are all significantly higher if the distribution of wealth is grounded in the principle of equal opportunity, instead of being grounded in the principle of equal outcome. Both of these insights may initially seem somewhat counterintuitive, as one might expect that wealth distribution inequality be lower if members in society all received equal share of the resources upon which they stumbled. However, the findings of this study imply that equality of opportunity in a capitalist society might create a more even distribution of wealth, as well as a greater degree of prosperity for its members.
\end{abstract}

Keywords: capitalism, wealth distribution inequality, equality of opportunity, equality of outcome, computer simulation

\section{Introduction}

Against the backdrop of calls for a more just form of capitalism, the purpose of this paper is to focus on the notion of equality within capitalist societies and to utilize findings from a computer simulation to explore which of one two fundamental principles, namely: (1) equality of opportunity; or (2) equality of outcome might better inform and guide reform efforts to create more uniform distribution of wealth among members of society. In today's global economy, which has recently experienced several major financial crises, those looking for more equitable alternatives are questioning the sustainability of modern capitalism. While there is a rising chorus of calls for an entirely different paradigm in which to ground the global economy, individuals who have had significant experience in global finance - such as Kenneth Rogoff, Professor if Economics and Public Policy at Harvard University and former Chief Economist at the International Monetary Fund, or Edmund Phelps, 2006 Nobel Prize Winner in Economics and Director of the Center on Capitalism and Society at Columbia University - do not see many viable options at present that can dethrone the dominant Anglo-American paradigm (Rogoff, 2012; Shah, 2011). Rogoff (2012) suggests that the most likely contenders might be Continental European Capitalism, "which combines generous health and social benefits with reasonable working hours, long vacation periods, early retirement, and relatively equal income distributions" or the Darwinian Capitalism that China employs, "with its fierce competition among export firms, a weak social-safety net, and widespread government intervention" (p.60).

According to Rogoff (2012), the fundamental issue is that "in the broad sweep of history, all forms of capitalism are ultimately transitional" (p. 60) and that what ever comes next has to be first and foremost has to be sustainable and - 
most importantly - not just equitable for this generation, but the one after it, in terms of the way wealth is distributed. Against the backdrop of such calls for a more just form of capitalism, this paper specifically focuses on the notion of equality within capitalist societies and utilizes findings from a computer simulation to explore which of one two fundamental principles, namely: (1) equality of opportunity; or (2) equality of outcome might better inform and guide reform efforts to create more uniform distribution of wealth among members of society.

\subsection{The Notion of Equality}

One of the most typical points of criticism directed towards capitalism is that it leads to inequality of wealth, a sentiment that often goes uncontested even by those who are ardent supporters of capitalism (Boudreaux, 2002). The debate in both academic and popular discourse is whether equality ought to be established in terms of where individuals finally end up or where they initially begin when pursuing the accumulation of personal wealth (Phillips, 2004). The notion of judicial equality suggests that "an individual's success in life be independent of irrelevant characteristics, that is, of characteristics that the individual should not be responsible for" (Calsamiglia, 2009, p. 273) - including race, gender, or parents.

A fundamental implication of this notion is that every individual in a given society should have the same chance to be equally successful (Berger, 1987). When assessing whether or not this type of equality exists in any given society, since it is difficult - if not impossible - to track how well each individual is doing, the evaluation is typically carried out in aggregate. The expectation is that - for ideal equality - the total wealth produced should be shared equally amongst all members of society.

When economists assess and report such equality (or inequality), one of the most widely accepted and used tools is the Gini Coefficient (Dorfman, 1979), named after the Italian statistician Corrado Gini, who developed the measure around the turn of the $20^{\text {th }}$ century (Gini, 1909). The Gini Coefficient is grounded in the Lorenz curve, which is a visual depiction of the gap between the ideal line of wealth distribution and the actual cumulative distribution for a given population (see Figure 1). The Gini Coefficient is the ratio of the area represented by the gap in relation to the total area of the triangle formed by the line of perfect equity and the two axes. In this visual representation, the further the Lorenz curve sways away from the line of perfect equity, the larger the gap gets - hence resulting in a larger Gini Coefficient, which suggests a greater inequality of wealth distribution. In an ideal society, where every member were to receive an equal share of the total wealth produced, the Lorenz curve would sit right on top of the perfect line of equity and the Gini coefficient would be zero.

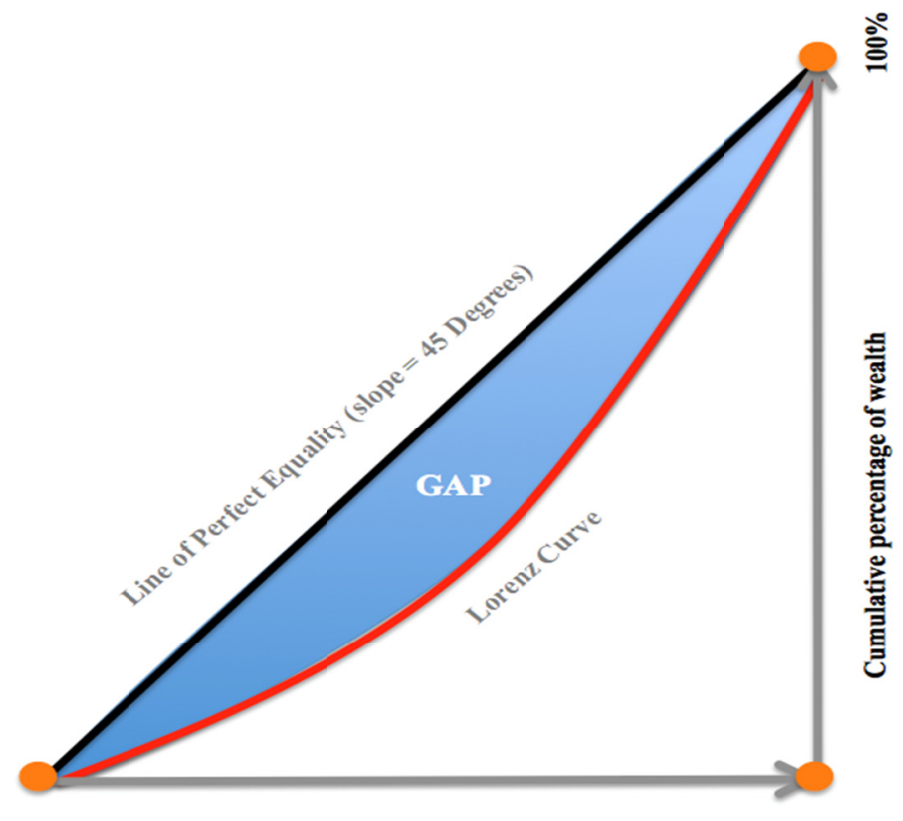

Cumulative percentage of individuals from lowest to highest wealth

$100 \%$

Figure 1. The Lorenz curve and the Gini coefficient

\subsection{Wealth Distribution and Equality around the Globe}

If one were to look at the economic data produced by the Organisation for Economic Co-operation and Development (OECD), which has been monitoring the economic and social wellbeing of people around the globe for the last 50 
years, it is easy to see that wealth distribution equality - for the majority of countries being tracked (17 out of 24) is not heading in the right direction (OECD, 2011a). As Table 1 illustrates, for many countries, the Gini Coefficient calculated in 2008 has gone up, compared to levels recorded in 1985. In its Inequality Report, OECD states that "income inequalities are one of the most visible manifestations of differences in living standards within each country" and that a high inequality in wealth distribution generally implies "a waste of human resources, in the form of a large share of the population out of work or trapped in low-paid and low-skilled jobs" (OECD, 2011a, p. 80).

It is likely an understatement to suggest that the global economy incorporates an intricate network of local economies that yields a very complex set of dynamics. Under the influence of these dynamics, the growing inequality in wealth distribution is pushing policymakers to come up with ways to create a more just and equal economic system (OECD, 2011b) - regardless of the type or extent of capitalism being employed in any given local economy. The fact still remains that any effort in this direction will inevitably have to take into account what type of equality needs to be set as a priority, when crafting new or revising existing policies.

Table 1. Gini coefficients and rankings of OECD countries

\begin{tabular}{|c|c|c|c|}
\hline COUNTRY & CURRENT RANK & 2008 LEVEL & +/- (1985 LEVEL) \\
\hline Australia & 26 & 0.34 & 0.64 \\
\hline Austria & 9 & 0.26 & 0.41 \\
\hline Belgium & 6 & 0.26 & 0.33 \\
\hline Canada & 23 & 0.32 & 0.40 \\
\hline Chile & 34 & 0.49 & - \\
\hline Czech Republic & 4 & 0.26 & 1.14 \\
\hline Denmark & 2 & 0.25 & - \\
\hline Estonia & 21 & 0.32 & - \\
\hline Finland & 8 & 0.26 & 1.16 \\
\hline France & 12 & 0.29 & -0.10 \\
\hline Germany & 15 & 0.30 & 0.72 \\
\hline Greece & 18 & 0.31 & -0.76 \\
\hline Hungary & 10 & 0.27 & -0.01 \\
\hline Iceland & 16 & 0.30 & - \\
\hline Ireland & 13 & 0.29 & -0.65 \\
\hline Israel & 30 & 0.37 & - \\
\hline Italy & 27 & 0.34 & 0.36 \\
\hline Japan & 24 & 0.33 & 0.37 \\
\hline Korea & 20 & 0.32 & - \\
\hline Luxembourg & 11 & 0.29 & 0.48 \\
\hline Mexico & 33 & 0.48 & - \\
\hline Netherlands & 14 & 0.29 & 0.32 \\
\hline New Zealand & 25 & 0.33 & 0.86 \\
\hline Norway & 3 & 0.25 & 0.54 \\
\hline Poland & 19 & 0.31 & - \\
\hline Portugal & 29 & 0.35 & -0.17 \\
\hline Slovak Republic & 5 & 0.26 & - \\
\hline Slovenia & 1 & 0.24 & - \\
\hline Spain & 22 & 0.32 & -0.53 \\
\hline Sweden & 7 & 0.26 & 1.10 \\
\hline Switzerland & 17 & 0.30 & - \\
\hline Turkey & 32 & 0.41 & -0.26 \\
\hline United Kingdom & 28 & 0.34 & 0.77 \\
\hline United States & 31 & 0.38 & 0.48 \\
\hline OECD Average & - & 0.31 & 0.33 \\
\hline
\end{tabular}

Source: OECD (2011a), Income inequality, in OECD Factbook 2011-2012: Economic, Environmental and Social Statistics, OECD Publishing.

The debate as to how a more uniform wealth distribution can be achieved - and at what economic, social, and political cost - will likely continue for the foreseeable future. Furthermore, whether the future of capitalism should embrace equality of opportunity or equality of outcome, when trying to create greater equality in wealth distribution, will likely be a dominant thread within that discussion. This study's findings hope to contribute to the conversation 
by depicting - through the use of computer simulation - the potential impact of how the choice between equal opportunity and equal outcome might impact wealth distribution.

\section{Methods}

In this study, Agent Based Modeling (ABM), as a form of computer simulation (Dooley, 2002), was used to explore how the fundamental principles of equality of opportunity or equality of outcome might impact wealth distribution in a capitalist society. The simulation model was coded in Java-based NetLogo language, which was originally developed by The Center for Connected Learning and Computer-Based Modeling at Northwestern University in Evanston IL (Wilensky, 2008). NetLogo, a cross-platform multi-agent programmable modeling environment, uses ABM to study the interaction between multiple heterogeneous agents, and the structures that emerge as a result of their interaction over time.

\subsection{Research Question and Hypotheses}

Based on the definition and nature of the variables investigated in this study, the main research question was: "How does the choice between the principle of equal opportunity and the principle of equal outcome influence wealth distribution (in)equality in any given society?" Answering this question required that the following hypotheses be tested:

- H1: There is a significant difference between the mean Gini Coefficient for societies where wealth is distributed based on the principle of equal opportunity and those where wealth is distributed based on the principle of equal outcome;

- H2: There is a significant relationship between the mean Gini Coefficient and population levels in all societies, irrespective of whether wealth is distributed based on the principle of equal opportunity or whether it is distributed based on the principle of equal outcome; and

- H3: There is a significant relationship between population sizes and the mean values for mean wealth, maximum wealth, and total wealth gained in all societies, irrespective of whether wealth is distributed based on the principle of equal opportunity or whether it is distributed based on the principle of equal outcome.

\subsection{Simulation Model}

The NetLogo model (Wilensky, 1998) programmed for this study was a variation of the Sugarscape model - an application of complexity theory to social sciences - aimed at observing social behaviors, while they emerge from a set of simple agent rules (Epstein \& Axtell, 1996). Individuals constituting the societies simulated in this study traveled around in a virtual lattice, seeking and collecting wealth over the course of a specific time period. Unlike the original Sugarscape model, individuals in this model were not programmed to consume any of their wealth throughout the simulation, in order to control for individual variance in consumption and solely focus on wealth accumulation. Whatever wealth individuals collected during the simulation remained with them until the very end of the simulation. The interface for the simulation is depicted in Figure 2.

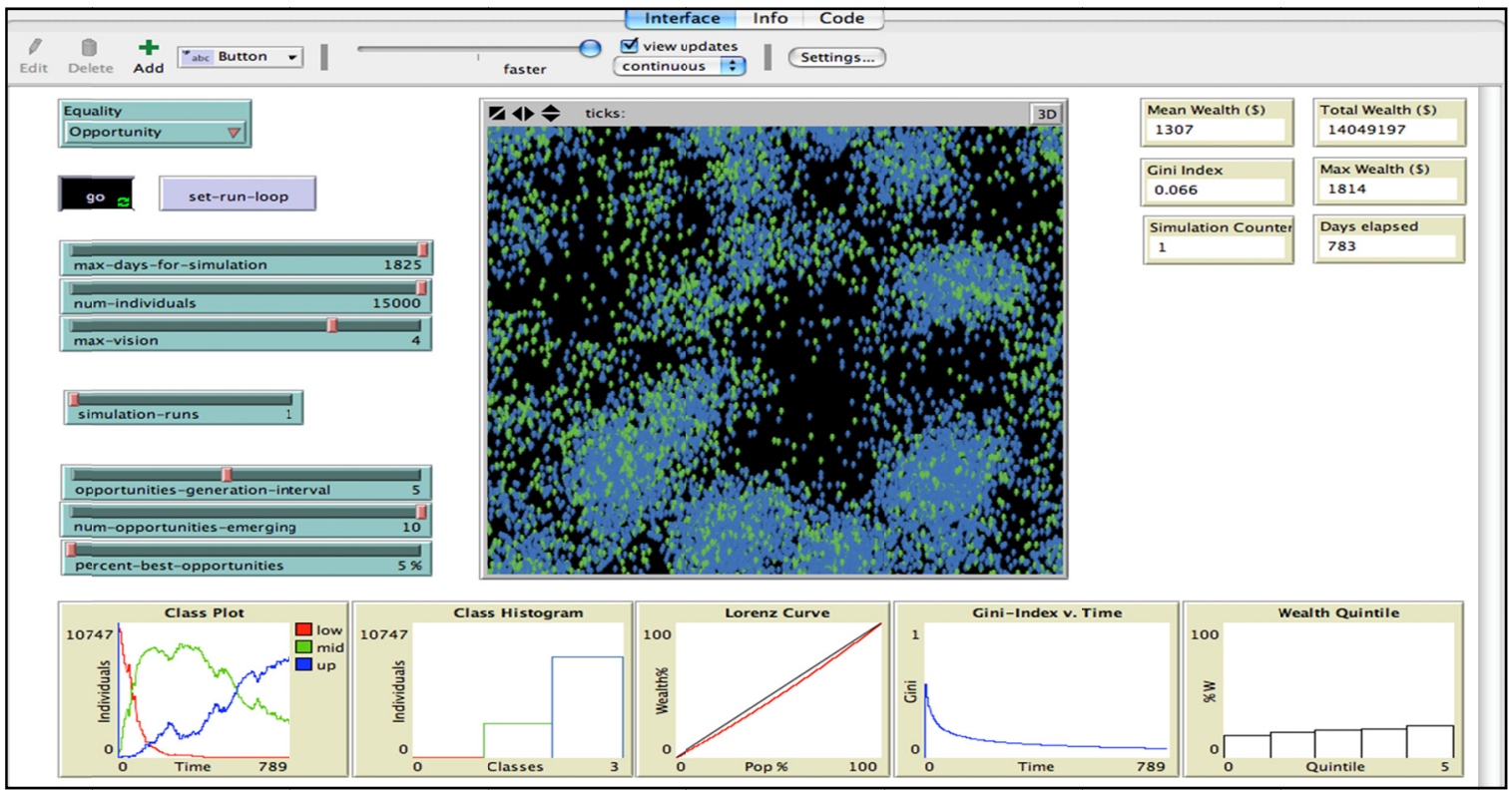

Figure 2. The simulation model interface 


\subsection{Simulation Runs}

A total of 800 simulations were run, where 400 of them incorporated the principle of EQUAL OPPORTUNITY and 400 incorporated the principle of EQUAL OUTCOME. Each of the 800 simulations covered a period of 5 years (i.e., 1825 days). For each simulation, the following initial conditions were set up:

- a random population between 2 and 15,000 individuals were randomly distributed across a virtual society lattice, consisting of 1680 cells (i.e., a 42 by 40 matrix);

- $\quad \$ 1$ of personal wealth was assigned to each individual; and

- a random amount of wealth between $\$ 1$ and $\$ 50$ was allocated randomly throughout the societal lattice.

Once each simulation started running, the individuals randomly positioned across the societal lattice behaved according to the following rules on any given day:

- individuals looked north, east, south, and west - within a range of four cells in each direction - to determine where the greatest potential wealth was positioned and proceeded one step in that direction (choosing a random direction, if all four directions presented the same potential);

- if the new cell on which an individual had landed contained wealth that could be collected and if no other individuals were present on that same cell, then the individual retained the entire amount of wealth available on that cell - however, if there were other individuals on that same cell and:

o if the wealth distribution principle for that simulation run had been initially set to EQUAL OPPORTUNITY, then only one of the individuals on that cell - randomly selected by the system retained the entire wealth available on that cell; or

$\circ$ if the wealth distribution principle for that simulation run had been initially set to EQUAL OUTCOME, then all the individuals on that cell retained an equal portion of the entire wealth available on that cell; and

- the wealth to be collected throughout the social lattice was regenerated and reallocated in a random manner for the new day that followed.

Figure 2 illustrates the difference in the wealth distribution logic between the two principles tested in this study. In the case of EQUAL OPPORTUNITY, all individuals landing on a cell have an equal chance of obtaining the total wealth available in the cell on which they land on any given day, but only (a randomly selected) one walks away with the total wealth. In the case of EQUAL OUTCOME, the total wealth available in the cell on which they land is equally divided amongst all and each walks away with an equal share. Needless to say, if only one individual lands on a cell (with no other individuals on that same cell) then both scenarios yield the same result - the individual walks away with the total wealth available in the cell.

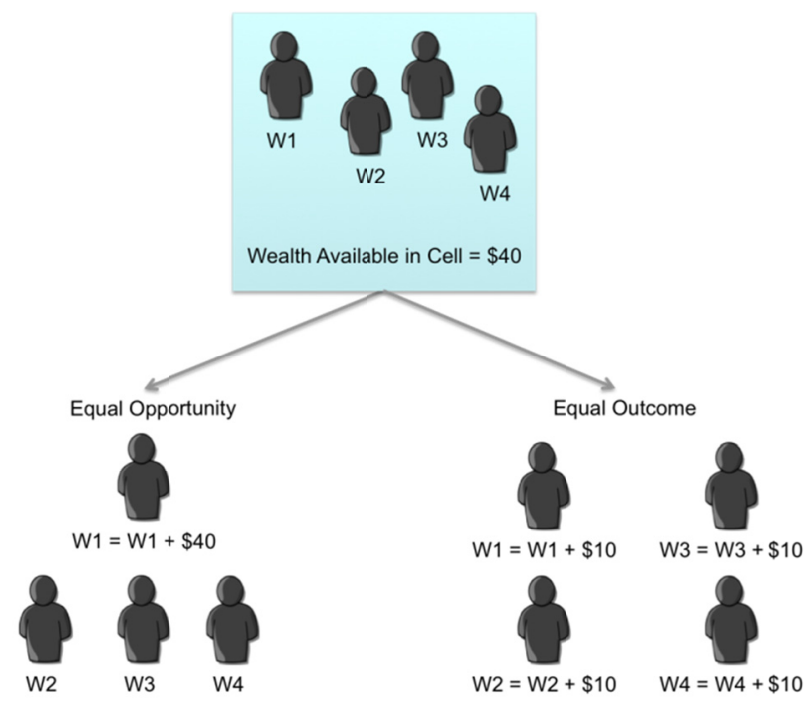

Figure 3. Equal opportunity versus equal outcome 


\subsection{Data Analysis}

At the end of each simulation run, the data collected for the corresponding 1825 days was stored in an IBM SPPS data file for subsequent analysis. The independent variables consisted of: population size and opportunity type. The dependent variables consisted of: Gini Coefficient, mean wealth, maximum wealth, and total wealth gained. Descriptive statistics (frequency analysis) and inferential statistics (correlation, t-tests, and ANOVA) were employed to analyze data collected for the 800 simulation runs. Histograms were produced to depict the differences in mean wealth and wealth quintiles for the wealth distribution principles examined in the study. Finally, graphs were also produced at each step of the simulation runs to monitor the Lorenz curve, Gini Coefficient, and wealth quintiles over time.

\subsection{Limitations}

The generalizability of the findings of this study will be limited, namely due to the fact that this is an experimental design that greatly simplifies a very complex set of social and economic dynamics. Without further research, it would be difficult to suggest that the findings of this study will apply for all real life scenarios. In particular, it should be noted that it is extremely challenging - if not impossible - to isolate and observe the effects of just the two principles - namely that of equal opportunity and equal outcome in economic transactions, while blocking out all other factors that might impact the way wealth is distributed. Undoubtedly, there are other individual, organizational, and environmental factors that will interact with, moderate, cancel out, or distort the effect of the variables examined in this study.

\section{Results}

The descriptives and correlations for the 400 equal opportunity runs are summarized in Table 2. For this group of runs, the key findings were: (a) population size was positively and significantly correlated with maximum wealth and total wealth; and (b) the Gini Coefficient was negatively and significantly correlated with mean wealth. The correlation amongst mean wealth, max wealth, and total wealth was positive and significant, as expected. All correlations were significant at $\mathrm{p}<.01$.

The descriptives and correlations for the 400 equal outcome runs are summarized in Table 3 . For this group of runs, the key findings were: (a) population size was positively and significantly correlated with the Gini Coefficient, but negatively and significantly mean wealth, maximum wealth and total wealth; and (b) the Gini Coefficient was negatively and significantly correlated with mean wealth, maximum wealth, and total wealth. The correlation amongst mean wealth, max wealth, and total wealth was positive and significant, as expected.

Table 3. Descriptives and correlations for EQUAL OUTCOME runs

\begin{tabular}{lccccccc}
\hline & M & SD & POP & GINI & $\begin{array}{c}\text { MEAN } \\
\text { WLTH }\end{array}$ & $\begin{array}{c}\text { MAX } \\
\text { WLTH }\end{array}$ & $\begin{array}{c}\text { TOT } \\
\text { WLTH }\end{array}$ \\
\hline POP & 7309 & 4379 & - & & & & \\
GINI & .170 & .065 & $.877^{* *}$ & - & & & \\
MEAN WLTH & 346 & 47 & $-.731^{* *}$ & $-.762^{* *}$ & - & & \\
MAX WLTH & 599 & 559 & $-.798^{* *}$ & $-.769^{* *}$ & $.983^{* *}$ & - & \\
TOT WLTH & $1 \mathrm{M}$ & $314 \mathrm{~K}$ & $-.577^{* *}$ & $-.402^{* *}$ & $.013^{* *}$ & $.139^{* *}$ & - \\
\hline
\end{tabular}

$\mathrm{N}=400$

** Significant $(\mathrm{p}<.01)$

As summarized in Table 4, a t-test conducted to compare the means for the Gini Coefficient, mean wealth, maximum wealth, and total wealth between the 400 equal opportunity runs and the 400 equal outcome runs revealed that the mean Gini Coefficient was significantly lower for equal opportunity runs and that the means for mean wealth, maximum wealth, and total wealth for the same group were significantly higher than those for the equal outcome runs. The $\mathrm{t}$ values were all significant at $\mathrm{p}<.001$.

Table 4. T-test between EQUAL OPPORTUNITY and EQUAL OUTCOME groups

\begin{tabular}{lrrrr}
\hline & EQ OPP & EQ OUT & \multicolumn{1}{c}{$\mathrm{t}$} & $\mathrm{df}$ \\
\hline GINI & .051 & .170 & $36.79^{* * *}$ & 798 \\
MEAN WLTH & 2939 & 346 & $-106.48^{* * *}$ & 798 \\
MAX WLTH & 3858 & 599 & $-112.71^{* * *}$ & 798 \\
TOTAL WLTH & $22 \mathrm{M}$ & $1 \mathrm{M}$ & $-34.242^{* * *}$ & 798 \\
\hline
\end{tabular}

$\mathrm{N}=400$ for each group

*** Significant $(\mathrm{p}<.001)$ 
As summarized in Table 5, an ANOVA test was conducted to compare the means for the Gini Coefficient, mean wealth, maximum wealth, and total wealth between the 400 equal opportunity runs - for the low ( 2 to 4999$)$, mid (5000 to 9999) and high (10000 to 15000) population size groups. The key findings were that: (a) the mean for the Gini Coefficient did not show significant variance by population size; and (b) the mean for mean wealth did not show significant variance by population size.

Table 5. ANOVA amongst population groups for EQUAL OPPORTUNITY

\begin{tabular}{lrr}
\hline & \multicolumn{2}{c}{ F } \\
\hline GINI & 3.02 & 399 \\
MEAN & .366 & 399 \\
WLTH & \\
MAX & $35.07^{* * *}$ & 399 \\
WLTH & \\
TOTAL & 399 \\
WLTH & \\
\hline for MID (5000 to 9999); N $=122$ for HIGH (10000 to 15000)
\end{tabular}

As illustrated in Figure 4, the plot of wealth quintiles for the low, mid, and high population size groups also supported the findings of the ANOVA test. Figure 4 shows that the wealth distribution remained the same regardless of population size.

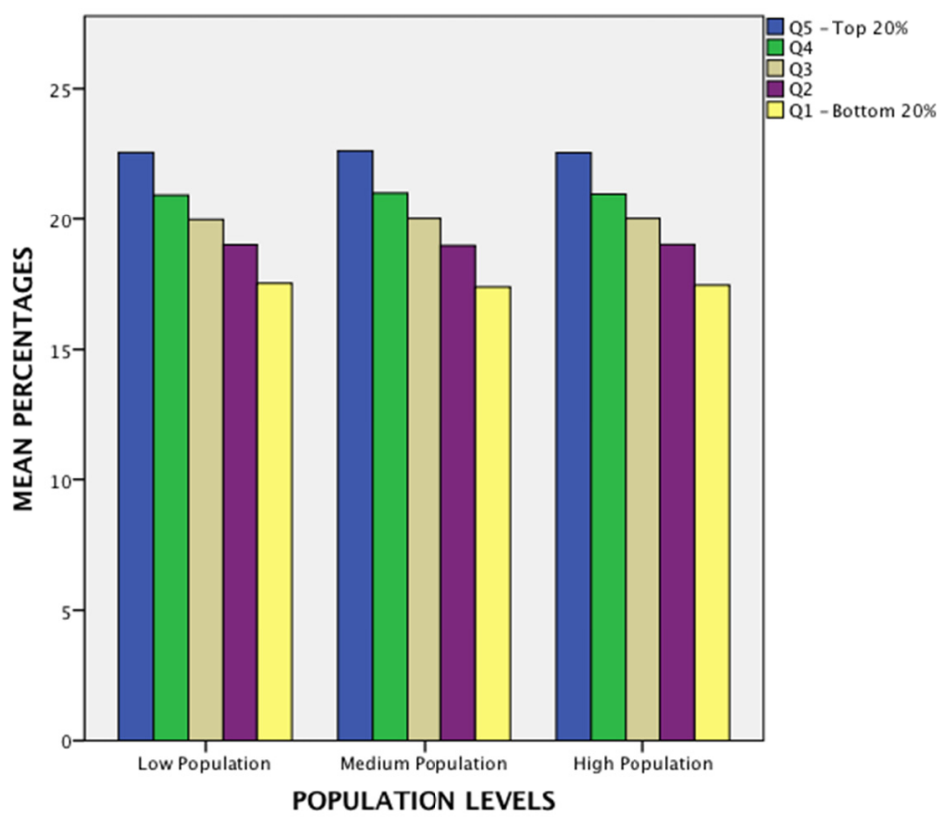

Figure 4. Wealth quintiles for EQUAL OPPORTUNITY

As summarized in Table 6 an ANOVA test was conducted to compare the means for the Gini Coefficient, mean wealth, maximum wealth, and total wealth between the 400 equal outcome runs - for the low (2 to 4999), mid (5000 to 9999) and high (10000 to 15000) population size groups. The key findings were that: (a) the mean for the Gini Coefficient showed significant variance by population size; and (b) the mean for mean wealth showed significant variance by population size.

As illustrated in Figure 5, the plot of wealth quintiles for the low, mid, and high population size groups also supported the findings of the ANOVA test. Figure 5 shows that the wealth distribution displayed variance by population size - with increasing wealth distribution inequality, as population size increased. 


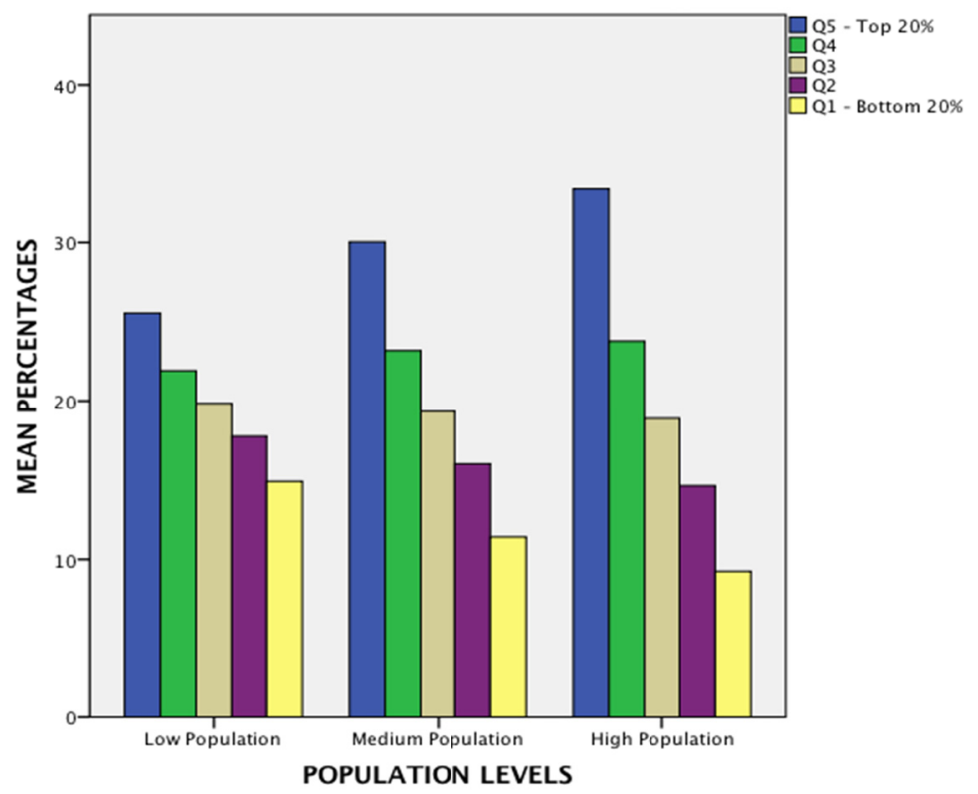

Figure 5. Wealth quintiles for EQUAL OUTCOME

Figure 6 presents a clear visual depiction of the way wealth was distributed differently between the equal opportunity runs and the equal outcome runs. Not only is the mean for the Gini Coefficient lower for equal opportunity, the range in which it fluctuates is also much narrower than the range observed for equal outcome. This graph provides further support to the ANOVA findings that while population size significantly and positively affects the Gini Coefficient for equal outcome runs, it has no significant impact for equal opportunity runs.

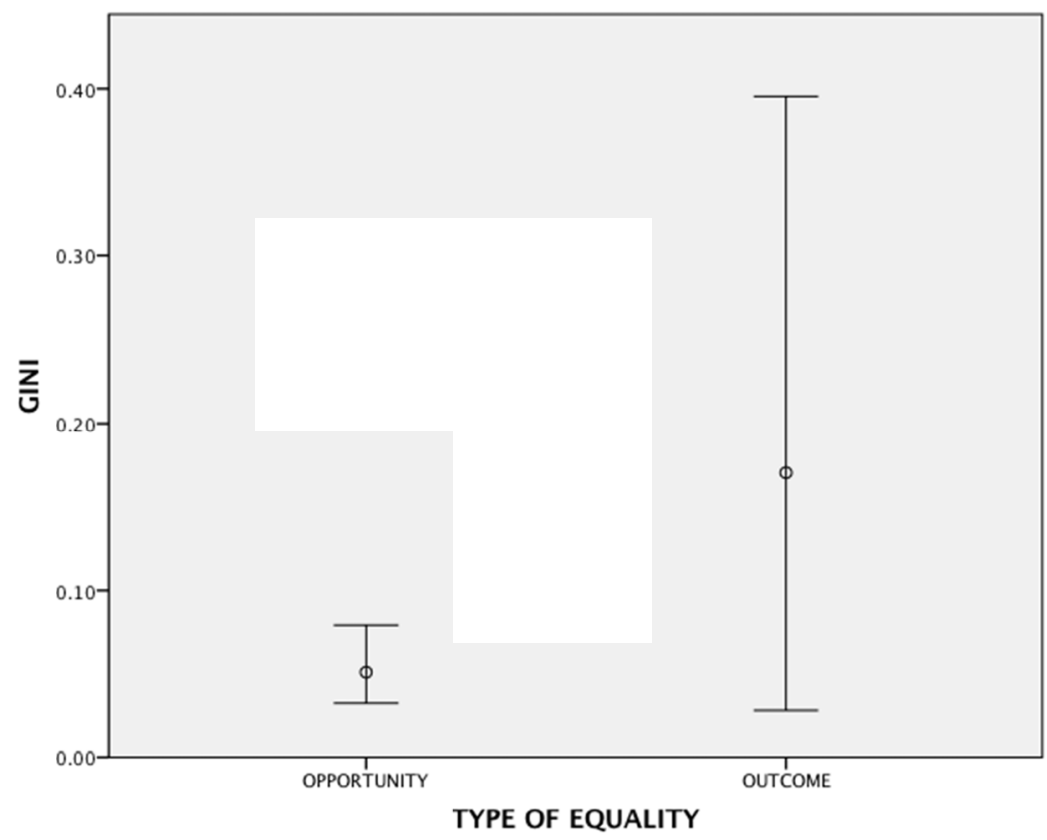

Figure 6. Gini coefficient range by type of equality

The final set of analyses conducted with data collected during the simulation runs consisted of histograms plotted for the mean wealth. As can be seen in Figure 7, the distribution of the 400 means recorded during the equal opportunity runs resembles a natural distribution. 


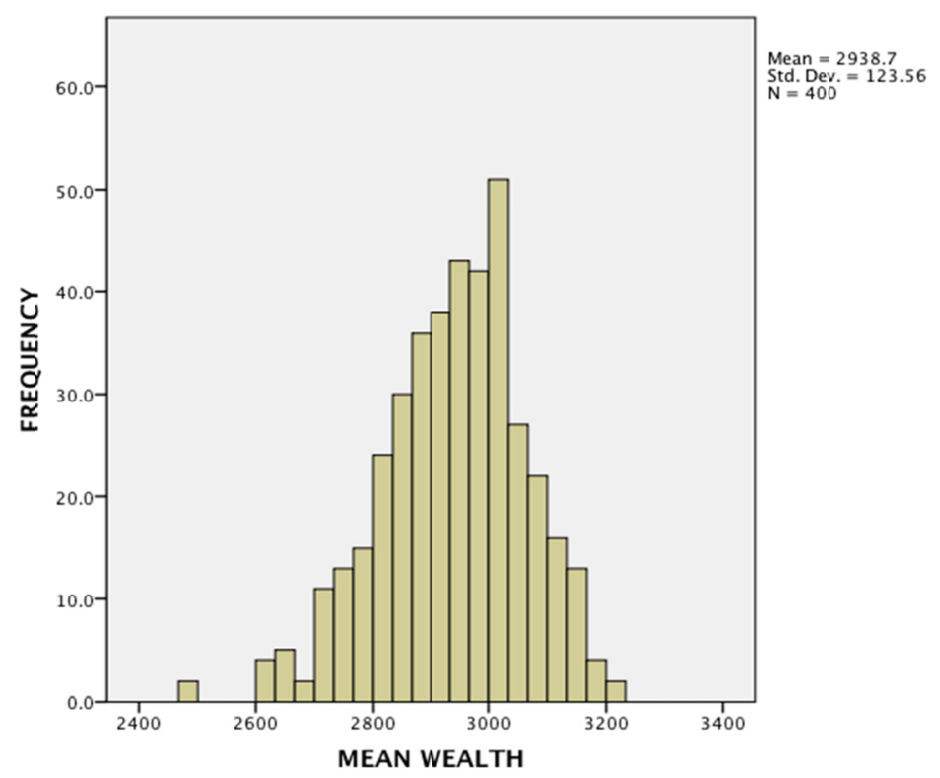

Figure 7. Histogram of mean wealth for EQUAL OPPORTUNITY

Meanwhile, as can be seen in Figure 8, the distribution of the 400 means recorded during the equal outcome runs resembles an exponential distribution.

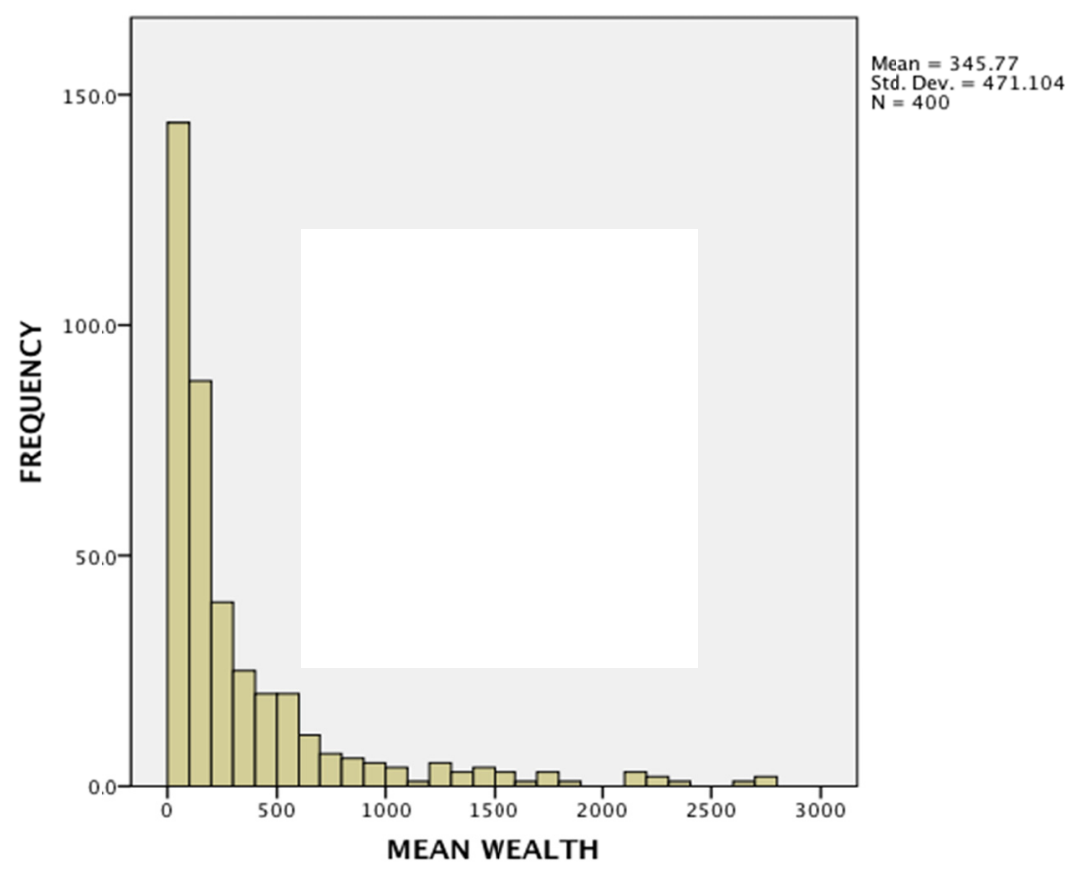

Figure 8. Histogram of mean wealth for EQUAL OUTCOME

\section{Discussion}

The results of the study support the first hypothesis that is a significant difference between the mean Gini Coefficient for societies where wealth is distributed based on the principle of equal opportunity and those where wealth is distributed based on the principle of equal outcome. Based on the findings, Gini Coefficients were significantly lower in instances where the wealth was distributed based on the principle of equal opportunity. The wealth distribution inequality was lower when the process was grounded in the principle of equal opportunity.

The results of the study partially support the second hypothesis that there is a significant relationship between the mean Gini Coefficient and population levels in all societies, irrespective of whether wealth is distributed based on 
the principle of equal opportunity or whether it is distributed based on the principle of equal outcome. While this relationship existed at a significant level for instances where the wealth was distributed based on the principle of equal outcome - with higher population levels leading to higher Gini Coefficients - the relationship was not significant for instances where the wealth was distributed based on the principle of equal opportunity. For equal opportunity runs, the Gini Coefficient did not change significantly with increases in population size.

The results of the study also provided partial support for the third hypothesis that there is a significant relationship between population sizes and the mean values for mean wealth, maximum wealth, and total wealth gained in all societies, irrespective of whether wealth is distributed based on the principle of equal opportunity or whether it is distributed based on the principle of equal outcome. The mean wealth, maximum wealth, and total wealth observed during the equal opportunity runs were all significantly higher than those observed during the equal outcome runs. However, the mean wealth in equal opportunity runs was not significantly related to population size, whereas in equal outcome runs it was.

\subsection{Implications}

The most interesting insight gained from this study is likely the finding that wealth distribution inequality is significantly lower if the distribution of wealth is grounded in the principle of equal opportunity, instead of being grounded in the principle of equal outcome. The other interesting finding is that the mean wealth, maximum wealth, and total wealth are all significantly higher if the distribution of wealth is grounded in the principle of equal opportunity, instead of being grounded in the principle of equal outcome. Both of these insights may initially seem somewhat counterintuitive, as one might expect that wealth distribution inequality be lower if members in society all received equal share of the resources upon which they stumbled. However, the findings of this study imply that equality of opportunity in a capitalist society might create a more even distribution of wealth, as well as a greater degree of prosperity for its members.

As indicated earlier, this simulation is an experiment that compares the two principles discussed in strong isolation from other economic and social factors. Therefore, it is not wise to make generalizations. However, the significant findings surfacing from this study might give researchers and policy makers something to think about the next time they engage in a discussion that involves the notion of equality. Friedman \& Friedman (1990) stated there were three categories for human equality: (1) equality in the eyes of God; (2) equality of opportunity; and (3) equality of outcome - accepting the first as the Creator's discretion, singling out the second as liberty and labeling the third as socialism. Friedman \& Friedman are not alone in their inclination to make such associations. Berger (1986) also defends equality of opportunity in pursuit of liberty and states that there is no evidence foe a Lorenz curve type of relationship between capitalism and development. While the findings of this study will not quell discussions as to whether individuals and societies are better off under the principle of equal opportunity, as they would be under the principle of equal outcome, it just might introduce a new perspective for both those defending and those opposing equality of opportunity.

\section{References}

Berger, P. (1986). The capitalist revolution: Fifty propositions about prosperity, equality, and liberty. New York: Basic Books.

Berger, P. (1987). America and the myth of inequality. In P. L. Berger (Ed.), Modern capitalism volume 1: Capitalism and equality in America (pp.1-14). Hamilton Press.

Bourreaux, D. (2002). Equality and capitalism. Ideas on Liberty, 52(9), 52-53.

Calsamiglia, C. (2009). Decentralizing equality of opportunity. International Economic Review, 50(1), 273-290. http://dx.doi.org/10.1111/j.1468-2354.2008.00530.x

Dooley, K. (2002). Simulation research methods. In J. A. C. Baum (Ed.), Companion to organizations (pp.829-848). Oxford: Blackwell.

Dorfman, R. (1979). A formula for the Gini coefficient. The Review of Economics and Statistics, 61(1). 146-149. http://dx.doi.org/10.2307/1924845

Epstein, Joshua M., \& Axtell, Robert. (1996, October 11). Growing artificial societies: Social science from the bottom up. Washington, DC: Brookings Institution Press.

Fiedman, M., \& Friedman, R. (1990). Free to choose: A personal statement. Boston, MA: Houghton Mifflin Harcourt. 
Gini, C. (1909). Concentration and dependency ratios (in Italian). English translation in Rivista di Politica Economica, 87(1997), 769-789.

Kenworthy, L. (2007). Is equality feasible? Contexts, 6(3), 28-32. http://dx.doi.org/10.1525/ctx.2007.6.3.28

Lorenz, M. O. (1905). Methods of measuring the concentration of wealth. Publications of the American Statistical Association (Publications of the American Statistical Association, 9(70), 209-219. http://dx.doi.org/10.2307/2276207

OECD. (2011a). Income inequality, in OECD Factbook 2011-2012: Economic, Environmental and Social Statistics. OECD Publishing.

OECD. (2011b). Divided We Stand: Why Inequality Keeps Rising. OECD Publishing.

Phillips. A. (2004). Defending equality of outcome. The Journal of Political Philosophy, 12(1), 1-19. http://dx.doi.org/10.1111/j.1467-9760.2004.00188.x

Rogoff, K. (2012). Is modern capitalism sustainable? The International Economy, 26(1), 60-61.

Shah, V. (2011). Capitalism - What comes next? Interview with Edmund Phelps. Thought Economics, September 2011. Retrieved from http://thoughteconomics.blogspot.com/2011/09/capitalism-what-comes-next.html

Wilensky, U. (1998). NetLogo Wealth Distribution model. Retrieved from http://ccl.northwestern.edu/netlogo/models/WealthDistribution Evanston, IL: Center for Connected Learning and Computer-Based Modeling at Northwestern University. 